\title{
Sir Arthur Conan Doyle, Sherlock Holmes y las enfermedades infecciosas
}

\author{
Walter Ledermann D.
}

\section{Sir Arthur Conan Doyle, Sherlock Holmes and infectious diseases}

Besides a pleasant author of best sellers, Sir Arthur Conan Doyle was a medical doctor, writing excellent short stories about the exercise of his profession in England. However, even he mentions The British Medical Journal and The Lancet in the Sherlock Holmes's stories, when in the plot introduces infectious diseases, Conan Doyle ignores important discoveries in the field of tetanus. Anyway, the appearing of infectious diseases in the adventures of the detective are rare: one mention of tetanus, another of leprosy and- the most analyzed in medical literature -a case of murder by inoculation of bacteria, probably the agent of melioidosis. Also he makes his hero discovers the toxic actions of a medusa and a transplant of solid organ. Little for a physician and less for an author who also wrote science fiction: it seems that the history of the great medical discoveries at the end of nineteenth century and beginning of the twentieth has passed by his side... and he just couldn't see it.

Key words: Conan Doyle, Sherlock Holmes, tetanus, mieloidosis, Cyanea.

Palabras clave: Conan Doyle, Sherlock Holmes, tetanos, melioidosis, Cyanea.
Hospital Luis Calvo Mackenna, Santiago. Chile. Laboratorio de Microbiología.

Recibido: 5 de agosto de 2010 Aceptado: 19 de agosto de 2010

Correspondencia a: Walter Ledermann Dehnhardt oncemayor@gmail.com
$\mathrm{S}$ ir Arthur Conan Doyle, "temple de acero, rectitud de espada", como escribiera su viuda en la lápida funeraria, fue un médico inglés nacido en mayo de 1859 y fallecido setenta años después, un soleado día de julio de $1930^{1}$. Como médico, hizo poco, y como escritor, hizo mucho, generalmente bueno, mas, para su gran decepción y pese a su enorme producción de novelas históricas y de las que hoy llamaríamos de ciencia-ficción, se le identificó, se le engrandeció y se le recuerda por uno de sus personajes más logrados: el detective Sherlock Holmes.

Conan Doyle vivió esa época de finales del siglo XIX, de grandes novelistas ingleses y, especialmente, de grandes cuentistas, como Saki, Rudyard Kipling, Somerset Maugham, Arnold Bennet, Wilkie Collins, Sheridan Le Fanu y hasta el mismísimo Dickens. El cuento era muy apreciado entre los ingleses y Conan Doyle lo cultivó con esmero, escribiendo notables relatos de médicos, que nos muestran el ejercicio de la medicina privada en Inglaterra, donde el doctor abría su consulta, ponía su cartelito en la puerta y día a día auscultaba al niño tuberculoso, sajaba el divieso al mozo, aliviaba el catarro de la anciana y, al caer la noche, subía a su coche e iba a atender el parto de una vecina. Pero dejemos los rodeos y vayamos al asunto: Conan Doyle se hizo famoso con los cuentos policiales protagonizados por Sherlock Holmes y el doctor Watson.

Se dice que el personaje del detective maestro en el arte de la deducción fue tomado de uno de sus profesores en la Universidad de Edimburgo, donde estudiaba medicina: el

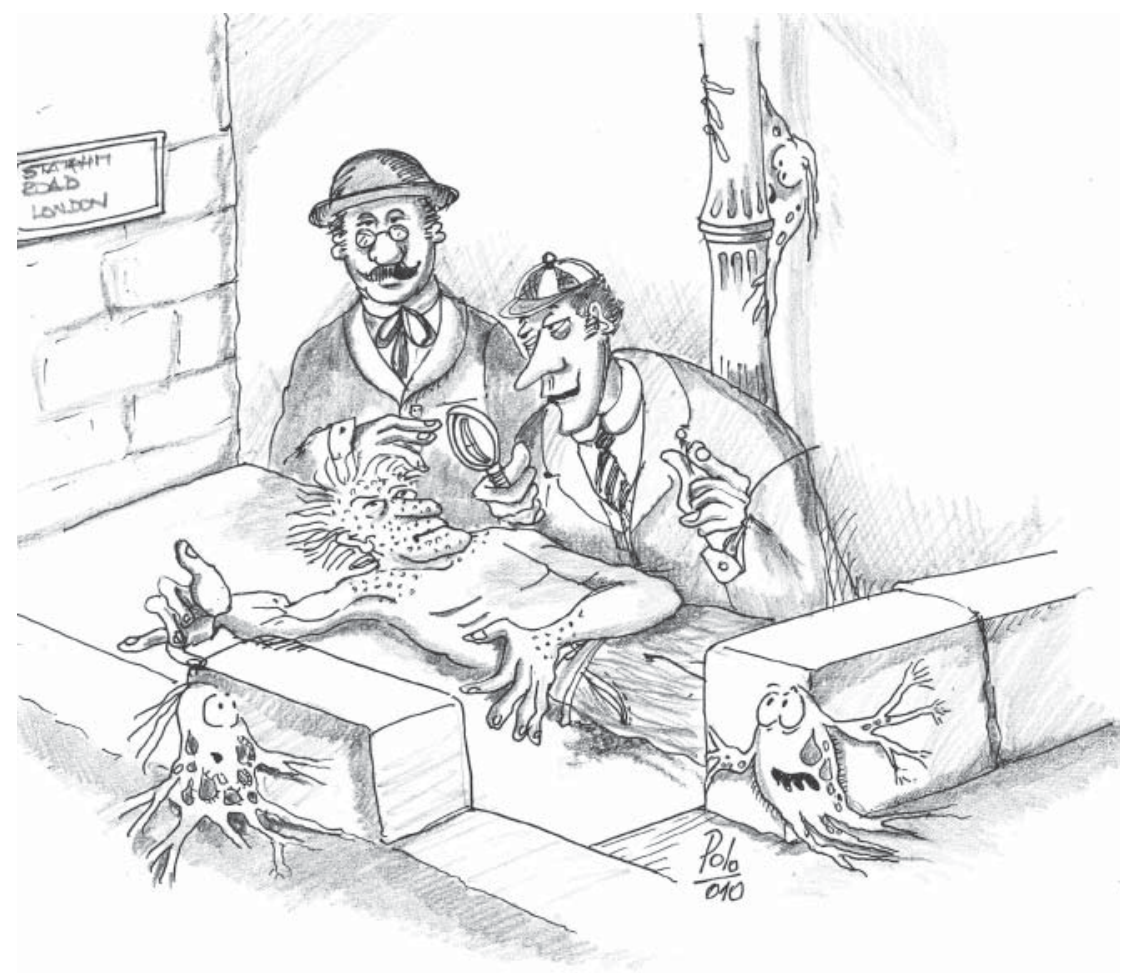

Dr. Joseph Bell, quien hacía hincapié en la observación, el acucioso examen visual del paciente, el análisis cuidadoso de su historia, derivando de ello en un diagnóstico certero, que nada dejaba a la adivinación, todo lo cual poco tiene de novedoso, pues representa la esencia de la medicina, tal como la enseñaba, por ejemplo, Sir William Osler ${ }^{2}$. 
En cuanto a Watson, simplemente eligió el prototipo, sin duda frecuente en su época, del médico militar, recto y tradicionalista, que regresa con su salud resentida luego de una larga estadía en las colonias tropicales. Pero el modelo de sus personajes poco importa: lo relevante es que éstos salvaron al autor de la miseria, pues en el ejercicio de su profesión iba de peor en peor, desde médico en barcos balleneros y cargueros, a la quiebra de su consulta y al sueño frustrado de hacerse oftalmólogo y enriquecer como tal en una elegante clínica londinense.

Que establecerse en Londres requería de un buen capital se describe muy bien, justamente, en una de las historias de Sherlock Holmes. En efecto, en El enfermo interno $^{3}$ se narra cómo un acaudalado mecenas ofrece al Dr. Trevelyn ponerle una casa amoblada, con consulta, servidumbre y gastos incluidos, todo a cambio del 75\% de las utilidades del ejercicio médico, trato económico que anticipa los "centros médicos" que hoy proliferan en nuestro país. No sabemos si alguien propuso a Conan Doyle semejante acuerdo; el hecho es que sin dinero no pudo establecerse como hubiera querido y, como al poco tiempo empezó a ganar bastante con la literatura, terminó por olvidar sus sueños médicos.

Sherlock Holmes llevó a Conan Doyle a la fama y a la buena vida. La ya citada edición Aguilar de 1964 ${ }^{1-3}$ presenta 56 cuentos y tres novelas con las aventuras del personaje; entre tantas historias, no faltan algunos relatos relacionados con la medicina, algo bastante lógico si se recuerda que, al fin y al cabo, el autor era médico: como tal, se dejó tentar por las posibilidades que para las tramas de misterio ofrecían las enfermedades infecciosas, todo un suceso a fines del siglo XIX, cuando Pasteur y Koch ponían de moda a las bacterias y sus toxinas. Sin embargo, casi todas las relaciones que veremos a continuación están entre las últimas del personaje y fueron escritas entrado ya el siglo XX, pareciendo que el autor recurrió a las enfermedades infecciosas cuando la temática se le estaba agotando.

Antes de pasar una "visita de médico" a dichas historias, es útil relatar una en que el autor enfrentó como médico a una de las peores enfermedades infecciosas: la tuberculosis. En 1885 el Dr. Doyle fue llamado a atender al joven Jack Hawkins, aquejado de una meningitis "terminal", vocablo que nos hace pensar en una larga evolución; como eran muchas las convulsiones, el médico se llevó el enfermo a su propia casa para atenderlo mejor y, con él, a la madre y a la hermana. El paciente murió, pero su hermana Louise se enamoró del abnegado médico y terminó casándose con él. Durante ocho años fueron felices, hasta que en 1893 se le diagnosticó tuberculosis a Louise, desgracia que abona la hipótesis de una meningitis de la misma etiología para el infortunado Jack, esto es, que los Hawkins eran un nido de bacilos de Koch. Como era costumbre entonces, el doctor Doyle llevó a su esposa y paciente a un sanatorio en Davos, Suiza, sin obtener mejoría alguna ${ }^{4}$. Ahora, que Conan Doyle era un escritor muy ameno pero de poco vuelo, como lo son hoy algunos célebres autores de best-sellers, lo demuestra el hecho que esta estancia en Davos no haya podido generar una novela de la talla de "La montaña mágica", la cual, entre sus muchas virtudes, tiene un interesante abordamiento microbiológico, todavía atractivo para los infectólogos chilenos $^{5}$. Y ahora sí, vamos a la ficción.

En la novela El signo de los cuatro ${ }^{6}$, los asesinos que robaron el tesoro de Agra se traicionan entre sí y el último sobreviviente, Jonathan Small, el hombre de la pata de palo, viaja a Londres a disputar el botín a los hijos del difunto Coronel Sholto. Lo acompaña como perro fiel un pigmeo de las islas Andaman, quien se introduce en casa de los Sholto a través de una claraboya y, enfrentado a la inesperada presencia de uno de los hermanos, lo mata disparándole un dardo emponzoñado con su cerbatana. Al encontrar el cadáver, rígido y con el rostro fijo en una espantosa mueca que remeda una sonrisa, el detective la describe como sonrisa hipocrática o risus sardonicus, como la llamaban los autores antiguos. No estaba descaminado Holmes, pues fue el Padre de la Medicina quien describió la enfermedad por vez primera en el siglo V a.C., relatando la historia de un patrón de barco que se atrapa un dedo con el ancla: Siete días más tarde aparece una descarga algo sucia; luego una molestia con su lengua, quejándose de no poder hablar con propiedad; sus mandibulas se deprimen juntas y sus dientes se cierran. Luego aparecen síntomas en su cuello y al tercer día hay opistótonos y sudoración. Seis días después de hecho el diagnóstico fallece ${ }^{7}$.

No obstante, cuando extrae la espina larga y negra clavada sobre la oreja del cadáver, Holmes demuestra un curioso desconocimiento de la etiología de la enfermedad al poner en boca del doctor Watson esta perla: la muerte ha sobrevenido por algún fuerte alcaloide vegetal... similar a la estricnina y que produce el tétanos, frase harto sorprendente en una novela publicada en 1890, cuando ya se conocía el bacilo tetánico.

La etiología infecciosa había sido propuesta en 1854 por Simpson; treinta años después, en 1884, Carle y Rattone toman muestras de la autopsia de un adolescente muerto de tétanos a raíz de haberse apretado una pustulilla del cuello, inoculando con ellas doce conejos, de los cuales once fallecen con la enfermedad, con lo cual concluyen que la materia de la herida tetánica es tetanógena ${ }^{8}$. El mismo año Nicolaier inocula con diversas tierras, donde suponía se encontraría el bacilo tetánico, una serie de 88 animales, entre ratones, conejos, cobayos y perros, falleciendo 64 de tétanos y siendo refractarios solamente los canes; si calentaba la tierra por una hora a $190{ }^{\circ} \mathrm{C}$, dejaba de ser infecciosa. Como no pudiera aislar el bacilo ni en la tierra ni en los animales fallecidos, 
concluye Nicolaier: visto que el bacilo no se disemina en el organismo enfermo, la enfermedad debe ser producida por una toxina similar a la estricnina... ${ }^{9}$. Entonces... ¿qué tanto sabía Conan Doyle? ¿Al publicar su novela y hablar de un alcaloide similar a la estricnina, sabía que Kitasato ya había identificado al bacilo toxigénico el año anterior, o se guió por la célebre enciclopedia médica de Eulenburg de 1886, donde se sostenía que para producirse el tétanos neonatal era necesaria una predisposición morbosa congénita, porque los niños robustos sufren infecciones del ombligo sin accidentes peligrosos, y que pueden provocar el tétanos los enfriamientos, la circuncisión y la plenitud excesiva de los senos... ${ }^{10}$. Al parecer, ya dedicado de lleno a la literatura, Conan Doyle no estaba muy al día en la literatura médica.

El autor volvió, muchos años después, sobre el tema de la cerbatana con dardos envenenados en La aventura del vampiro de Sussex ${ }^{11}$, narrando cómo un muchacho celoso los arrojaba sobre su hermanastro menor, succionando la atribulada madre con sus labios el veneno desde el cuello de la criatura, acción que llevó al marido a suponerla "vampiro". En esta historia el veneno era curare o alguna otra droga siniestra; el la novela anterior, nos quedamos en ayunas, pues nunca se dice qué droga usó Togo para matar a Sholto. Por supuesto, se han elaborado hipótesis variadas: recientemente George B. Koelle ha postulado la estrofantina, droga similar a la digital, y dos estimulantes del sistema nervioso central, como la picrotoxina y, de nuevo, la estricnina, afirmando que probablemente sería absorbida a gran velocidad por la herida, produciendo la muerte por parálisis tónica respiratoria, luego de varias convulsiones violentas ${ }^{12}$.

Pasemos a La aventura del detective moribundo ${ }^{13}$, publicada en 1917, el caso más comentado por los infectólogos. Culberton Smith, un plantador de Sumatra en la última década del siglo XIX, quien, sin ser médico, se ha especializado en enfermedades tropicales, mata a su sobrino enviándole una cajita que, al abrirse, inocula a su víctima con un letal cultivo bacteriano. Los síntomas son abigarrados: fiebre alta, postración, carfología, disfonía, disnea... N.J. Ehrenkranz, uno de los investigadores de esta historia estableció las circunstancias bacteriológicas de este crimen: la enfermedad era $100 \%$ mortal, transmisible por inoculación percutánea, causaba la muerte en cuatro días y no era conocida por esa época ${ }^{14}$. Holmes, que se finge afectado por ella, pregunta al Dr. Watson, cuando éste le ofrece su ayuda médica:

- ¿Tendré que demostrarle su propia ignorancia? ¿Qué sabe usted, digame, de la fiebre de Tapanuli? ¿Qué sabe usted de la podredumbre negra de Formosa?

No os molestéis, lectores, en buscar ni la fiebre ni el lugar geográfico, pues nunca hubo tal fiebre de Tapanuli. En cuanto a la de Formosa, quizás oyó el Dr. Doyle hablar alguna vez de las fiebres hemorrágicas de Oriente, como las causadas por virus del tipo Hantaan. ¿Entonces, qué enfermedad infecciosa pudo haber tomado el escritor para su fiebre de Tapanuli?

En 1967 Ober propuso como etiología la Rickettsia tsutsugamushi, causante de la fiebre del mismo nombre ${ }^{15}$; en 1994 Sodeman la descartó elegantemente, proponiendo en su lugar la melioidosis ${ }^{16}$; y recientemente Setu K Vora ${ }^{17}$, quien pareciera no haber leído al anterior, coincide en que la fiebre de Tapanuli pudo ser esta enfermedad tropical, descrita en 1912 por Whitmore y Krishnaswami entre los morfinómanos de Rangoon.

El análisis de estos autores es excelente y las coincidencias con el caso del infortunado Savage son sorprendentes, pero uno se pregunta por qué habría Conan Doyle inventado una enfermedad desconocida si tenía a mano la melioidosis, cuyo agente había sido descrito como Bacillus pseudomallei en 1913, año que Ehrenkranz y Vora suponen escrito el cuento (se publicó en 1917), a menos que no estuviera al día en los descubrimientos microbiológicos, en una era pre-internet. Después de la descripción original de 1912 y de su hallazgo en los cadáveres de drogadictos llevados a la morgue de Rangoon, la bacteria reaparece en 1913 en Kuala Lumpur, como epizootia entre los animales - cobayos y conejos- de un laboratorio. En 1917 Stanton describe los primeros casos humanos en Kuala Lumpur, identifica al bacilo y reproduce por inoculación experimental la enfermedad en varios animales. De allí la melioidosis pasa a Birmania y a Ceilán; en 1921 Stanton y Fletcher proponen el nombre de Bacillus whitmori ${ }^{18}$. Con el tiempo la bacteria se llamaría Pseudomonas pseudomallei y, actualmente, Burkholderia pseudomallei... ¡Qué manera de molestar, estos taxonomistas!

Ahora bien, después de todo, como estos hallazgos y descripciones iniciales se produjeron casi simultáneamente con la escritura del cuento, es posible también que, sabiéndola enfermedad desconocida para la gran masa lectora, Doyle haya inventado el nombre, muy superior a melioidosis, de fiebre de Tapanuli: proponemos formalmente rebautizarla así.

Volviendo a Ehrenkranz, éste deduce que la bacteria crecía a temperatura ambiente, estaba sembrada en gelatina y resistió las variaciones ambientales del largo viaje de Sumatra a Londres, descartando como hipótesis diagnósticas, la fiebre Tsutsugamushi, pues la Rickettsia no crece en gelatina y es letal sólo en $60 \%$, y elimina también el carbunclo, ya muy conocido en esa época, para terminar proponiendo la peste bubónica, aunque, como el anterior, también era ampliamente conocida.

El artículo mereció una graciosa réplica, publicada en la misma revista, de parte del mismísimo Dr. Watson, quien se burla de su hipótesis: Hace poco me hizo reír hasta las lágrimas su artículo sobre muerte por infección 
tropical... Culberton Smith no era, como usted deduce, un laboratorista competente....era un bacteriólogo descuidado, que continuamente contaminaba muestras con hongos, que adquiría como resultado de su absorbente interés en la crianza de palomas... el agente del "mal asiático fuera de lo común" fue un cultivo de Branhamella catarrhalis, mezclado con Penicillium islandicum y Penicillium rugulosum... la muerte fue debida a falla hepática y encefalopatía, totalmente concordante con el efecto de micotoxinas y el cuadro clínico no era diferente al del $S$. de Reye... Watson termina su carta diciendo que fue Smith quien, años más tarde, contaminara un cultivo de Fleming, dando así nacimiento a la penicilina. Ehrenkranz escribió con buen humor, una contrarréplica a Watson, pero ésta, como diría Kipling, es otra historia.

Cronológicamente, sigue La aventura del soldado de la piel decolorada, que es de $1929^{19}$. James Dodd viaja a la mansión señorial de los Emsworth en busca de Godfrey, ex compañero de armas en la guerra boer, pero es mal recibido por el padre, quien niega la presencia del joven y exclama:

\section{- ¡Pluguiera a Dios que hubiera muerto!}

Sin embargo, Dodd ve el rostro de su amigo en la ventana, tan pálido y blanco como si fuera un fantasma. De esta descripción, por los antecedentes de la estancia en Africa, y por haberle su amigo visto leer un periódico que podría ser el Lancet o el British Medical Journal, Holmes deduce que el joven Emsworth tiene lepra y por ello lo esconden. El detective logra que un famoso especialista vea al soldado de piel decolorada y el diagnóstico es salvador: Emsworth no tiene lepra, sino pseudolepra o ictiosis. Como el soldado se había metido por error en Africa a un hospital de leprosos, se suponía contagiado: se deprimió y su aprensión produjo una acción física que estimula precisamente lo que se teme... ¡Enfermedad psicosomática! El doctor Doyle se adelanta a su época. Como historia de Sherlock Holmes no tiene mucho misterio, pero la importancia que el detective le da al periódico que se lee en la habitación del enfermo es, sencillamente, una perla.

Antes de incluir La aventura de la melena del león ${ }^{20}$ en esta revisión, consultamos con una distinguida parasitóloga si el estudio del agente etiológico de este caso pertenecía a la parasitología; con algunas reticencias, nos contestó que sí; también hemos encontrado el tema al menos en un texto de infectología; volveremos luego sobre esta dudosa asignación.

La singular historia ocurre cuando Holmes, ya retirado y sin la ayuda de Watson, vive solo en una casita junto a los acantilados de Sussex. Al retirarse las aguas tras un temporal han quedado varias pozas entre los roqueríos, en las que suelen bañarse profesores y alumnos del colegio local. En uno de sus paseos matutinos, Holmes auxilia al profesor de biología, quien parecía haber recibido una terrible azotaina mientras se bañaba, pues tenía toda la espalda cubierta de líneas amoratadas, como si hubiese sido terriblemente vapuleado con un azote de alambre fino...Antes de fallecer, la víctima balbucea frases incomprensibles, que terminan en un chillido espantoso:

- ¡La melena de león!

De este desdichado se da el antecedente que había visto arruinada su vida por un padecimiento cardíaco que siguió a unas fiebres reumáticas, es decir, era con gran probabilidad un mitrálico, precioso detalle que el Dr. Doyle proporciona al lector para entender por qué un hombre puede morir tan rápido a causa de unos azotes.

Posteriormente, mueren en el mismo sitio el perro del profesor y el de matemáticas es herido en la misma forma, pero sobrevive bebiendo aguardiente a mares. Para entonces ya Holmes había recordado de sus múltiples lecturas un libro del célebre viajero J.G. Word, donde éste describía el ataque de una Cyanea capillata: Si el bañista distingue una masa, como redonda y suelta, de membranas y de fibras de color leonado, algo como unos grandes manojos de melena de león y de papel plateado, que se ponga en guardia...

Esta Cyanea capillata (C. lamarckii, Linneo 1758), llamada vulgarmente "melena o crin de león”, es la más grande de las medusas, habiéndose encontrado en la bahía de Massachussets en 1870 una cuyos tentáculos alcanzaban una longitud de 36,5 metros, convirtiéndola en el animal más grande del mundo, superando en longitud a la ballena azul. Cada tentáculo tiene millones de nematocistos, células urticariantes rellenas de veneno, que inyecta en la piel de su víctima gracias a una especie de dardo, causando parálisis muscular y, eventualmente, la muerte por paro respiratorio ${ }^{21}$. Su hábitat son las aguas profundas del Ártico, no pudiendo explicar el buen Sherlock qué hacía esta medusa en las costas de Sussex, diciendo solamente que las subida de las aguas la dejó atrapada en la piscina natural en que se bañaron los desdichados profesores, tras lo cual la ubica y la mata arrojándole una roca de buen tamaño.

Quizás hemos forzado un poco el campo de la infectología al meter una medusa en este artículo, lo cual nos trae a la memoria la definición de las enfermedades infecciosas que hiciera el recordado Profesor Kraljevic en su primera clase en la Universidad Católica : Enfermedad infecciosa es todo proceso patológico causado por un agente patógeno vivo. De inmediato fue refutado por "un alumno de pensamiento inquieto":

- ¿Si en una corrida de toros el torero recibe una cornada, el toro sería "un agente patógeno vivo"?22.

Recordando esta sagaz objeción, hemos dejado fuera La aventura del pie del diablo, un caso de envenenamiento familiar con un polvo misterioso traído de África, que casi 
mata al buen Watson ${ }^{23}$, pero no podemos omitir la graciosa Aventura del hombre que reptaba ${ }^{24}$, por su valor médico e histórico, al presentar un antecesor fallido del viagra.

El anciano y celebérrimo fisiólogo Presbury es agredido dos veces por su fiel perro lobo; después empieza a reptar, caminando sobre sus manos y pies; luego escala murallas con sorprendente agilidad. La respuesta al enigma es que el profesor, como tanto necio que se niega a aceptar su vejez, se inyectaba suero del mono langur carinegro, animal que repta y trepa. La historia suena ridícula, pero tras ella se esconde una increíble realidad: el trasplante con "glándulas de mono" del famoso Profesor Voronoff.

El cuento fue escrito en los años veinte; mucho antes, en 1889 el célebre fisiólogo Brown-Séquard, el del famoso síndrome, buscando a los 72 años la juventud perdida, se inyectó en forma subcutánea un extracto acuoso de testículos de perro y cobayo: éste fue, sin duda, el modelo para el reptante profesor Presbury. Pero la motivación para el cuento no vino de la auto-inoculación de BrownSéquard, sino de los trasplantes de "glándulas de mono", que venía realizando con gran sensación el médico ruso Serge Voronoff. En efecto, convencido que los testículos, además de generar espermios, tenían acción vigorizante sobre todo el organismo, el ruso pensó implantar en los ancianos testículos de mono, animal físicamente superior al hombre en fuerza y salud.

Realizó su primer trasplante, o mejor dicho, su primer injerto, el 12 de junio de 1920. Cortó el testículo en tiras de 2 por $0,5 \mathrm{~cm}$, con las cuales hizo dos implantes en el escroto del paciente. Convencido de su éxito, ya que el injerto prendió, hizo otros 40 en una década, entre ellos a ¡siete médicos!.. Feliz con su naciente gloria, Voronoff formó su criadero de monos, escribió un libro y, por último, perdido ya todo norte, trasplantó un ovario de mona en una mujer estéril y luego la inseminó (con semen humano, no de mono, y tampoco suyo) sin éxito. Entre tanto, llevados por la ilusión y la vanidad humana, miles de hombres maduros y más que maduros se operaron en varios países, incluso en Chile, hasta que, pasada la autosugestión, los injertados se dieron cuenta del fracaso, envejecieron igual y la técnica cayó en el descrédito ${ }^{25}$. A ellos quiso satirizar el doctor Conan Doyle con el hombre que reptaba.

Y eso es todo. Poquísimo, considerando la extensa obra de un autor médico que menciona al Lancet y al British Medical Journal, publicaciones que aparentemente leía y donde encontraría muchas noticias de la historia que, con sus espectaculares descubrimientos estaban escribiendo los microbiólogos. Pareciera que Sir Arthur Conan Doyle, escritor tanto de novelas históricas como de ciencia ficción ${ }^{26}$, no fue capaz de ver como la historia y la ciencia pasaban por su lado, presagiando un vertiginoso desarrollo científico en el porvenir.

\section{Resumen}

Sir Arthur Conan Doyle, además de ameno escritor de best sellers, era médico y escribió excelentes cuentos sobre el ejercicio de su profesión en Inglaterra. Sin embargo, a pesar de mencionar The British Medical Journal y The Lancet en sus historias de Sherlock Holmes, al introducir enfermedades infecciosas en sus tramas, ignora descubrimientos importantes ya realizados en su época en el campo del tétanos. En todo caso, las apariciones de las enfermedades infecciosas en las historias del detective son escasas: una mención del tétanos, otra de la lepra y -la más analizada en la literatura médica- un caso de asesinato realizado mediante la inoculación de una bacteria, probablemente del agente de la melioidosis. También hizo a su héroe descubrir las acciones tóxicas de una medusa y de un trasplante de órganos. Poco para un médico y poco para un autor que también escribía ciencia ficción: pareciera que la historia de los grandes descubrimientos médicos de fines del siglo XX y comienzos del XXI pasó por su lado... y no la vio.

\section{Referencias}

1.- Lázaro Ros A. Hitos en la vida ejemplar de Sir Arthur Conan Doyle. En: Doyle AC. Sherlock Holmes. $4^{\mathrm{a}}$ ed. Aguilar, Madrid 1964; II: 9-43.

2.- Lázaro Ros A. Nacimiento e inmortalidad de Sherlock Holmes. En: Doyle AC. Sherlock Holmes. $4^{\mathrm{a}}$ ed. Aguilar, Madrid 1964; I: 9-30.

3.- Doyle A C. El enfermo interno. En: Sherlock Holmes. $4^{\mathrm{a}}$ ed. Aguilar, Madrid 1964; I: 740-59.

4.- Lellenberg J, Stashower D, Foley C. Arthur Conan Doyle: A life in letters. Harper Press, London 2007.

5.- Mella S. Mis libros, el terremoto y lo que vino después. Rev Chil Infect 2010; 27 (3): 233-4.

6.- Doyle A C. El signo de los cuatro. En: Sherlock Holmes. $4^{\mathrm{a}}$ ed. Aguilar, Madrid 1964; I: 163-283.

7.- Laín Entralgo. La medicina hipocrática. Salvat Editores S.A., Madrid 1970.

8.- Bulloch W. History. En: Fildes P. Bacillus tetani. Medical Research Council. A System of Bacteriology in relation to Medicine. His Majesty's Stationery Office, London 1929; 3 (X): 298-300.

9.- Nicolaier A. Über die Bacillus tetani. Dtsch Med Wochenschr 1884; $10: 842-52$.

10.- Eulenberg A. Tétanos. Diccionario Enciclopédico de Medicina y Cirugía prácticas, Agustín Jubera editor, Madrid 1886; XII: 405-15.

11.- Doyle A C. La aventura del vampiro de Sussex. En: Doyle AC. Sherlock Holmes. $4^{\mathrm{a}}$ ed. Aguilar, Madrid 1964; II: 919-39.

12.- Klinger L S. Conan Doyle. Sherlock Holmes anotado. Ed. Akal 2009; p. 278.

13.- Doyle AC. La aventura del detective moribundo. En: Doyle AC. Sherlock Holmes. $4^{\mathrm{a}}$ ed. Aguilar, Madrid 1964; II: 717 35 . 
14.- Ehrenkranz N J A. Conan Doyle, Sherlock Holmes, and murder by tropical infection. Rev Infect Dis 1987; 9 (1): 222-5.

15.- Ober W B. Conan Doyle's dying detective: problem in differential diagnosis. NY State J Med 1967; 67: 2141-45

16.- Sodeman W A Jr. Sherlock Holmes and tropical medicine: a centenal appraisal. Am J Trop Med Hyg 1994; 50:99-101.

17.- Setu K. Vora. Sherlock Holmes and a biological weapon. J R Soc Med 2002; 96: 101-103

18.- Fletcher W. Melioidosis. En: A system of bacteriology in relation to medicine, vol V. His Majesty's Stationery Office, London 1930; p.56.

19.- Doyle A C. La aventura del soldado de la piel decolorada. En: Sherlock Holmes. $4^{\mathrm{a}}$ ed. Aguilar, Madrid 1964; II: 853-75.

20.- Doyle A C. La aventura de la melena del león. En: Sherlock
Holmes. 4ª ed. Aguilar, Madrid 1964; II: 1021-43.

21.- Hickman C P, Ober W C, Garrison C W. Principios integrales de zoología. $3^{\mathrm{a}}$ edición. Mc Graw Hill - Interamericana, Madrid 2006; XVIII: 1022

22.- Kraljevic R. Memorias de un viejo infectólogo. Pfizer, Santiago 1998; p.116.

23.- Doyle A C. La aventura del pie del diablo. En: Sherlock Holmes. $4^{a}$ ed. Aguilar, Madrid 1964; II: 763-93.

24.- Doyle A C. La aventura del hombre que reptaba. En: Sherlock Holmes. $4^{a}$ ed. Aguilar, Madrid 1964; II: 995-1019.

25.- Thierry Gillyboeuf. The famous doctor who inserts monkeyglands in millionaires. Spring. New series. 2000; 9: 44-5.

26.- Doyle A C. La zona ponzoñosa. Cuando la Tierra lanzó alaridos. La máquina desintegradora. El abismo de Maracot. En: Novelas de aventuras. 4ª ed. Aguilar, Madrid 1964. 